\title{
Performance of Respirator Filters Using Quality Factor in Korea
}

\author{
Don-Hee HAN
}

Department of Occupational Health and Safety, Inje University, Kyongnam-do, Kimhae, 621-749, South Korea

Received March 6, 2000 and accepted September 5, 2000

\begin{abstract}
A respirator filter of good quality has not only high aerosol collection efficiency but also low air resistance. "Quality factor", which is expressed with aerosol penetration and pressure drop, can be used to rank the performance of respirator filters within the same category. This study focuses on evaluating several respirator filters which are widely used in Korea using quality factor. Two mechanical filters and three filtering facepieces made by different manufacturers were measured aerosol penetrations and pressure drops by an automatic filter tester (CertiTest Model 8110, TSI Inc., St. Paul, USA) at four flow rates of 10, 32, 64 and $85 \mathrm{~L} / \mathrm{min}$. $\mathrm{NaCl}$ aerosols used were reported to be mean size of $0.1 \mu \mathrm{m}$ and geometric standard deviation of $<1.9$. The penetrations and pressure drops of all filters have strong flow rate dependency. The filter quality factors decrease sharply as flow rates are increased. The mechanical filter $S$ and filtering facepiece $M$ are shown better filter quality than others in the same category. Since some certified filters are found to be inappropriate in the workplace exposed to fume, this result suggests that the current certified filter test protocol for respirators should be changed for the new protocol using smaller aerosols.
\end{abstract}

Key words: Respirator filter, Quality factor, Collection efficiency, Pressure drop, Aerosol

\section{Introduction}

In the workplace in which effective engineering controls are not feasible, an appropriate respirator must be used. Particulate respirator filters are used for protection against dusts, fumes and/or mists. The most common type of respirator filters used widely in Korea is filtering facepiece, also referred to as "disposable respirator", which is the lightest, least burdensome, and therefore, the most popular type of respirators preferred by workers. Filtering facepiece presently most available is a flat disk of compressed synthetic fiber felt, to which an electrostatic charge is imparted to increase efficiency during manufacture by impregnating the material and mechanically beating or needling $\mathrm{it}^{1)}$. Filtering facepiece does not affect the mobility of the wearer and may present little physiological strain to the wearer. But performance of fibrous filters imparted by electrical charge

*To whom correspondence should be addressed. may deteriorate during use because of water vapor, high temperature, oil mist and some chemicals in the workplace atmosphere ${ }^{2,3)}$. Another type of respirator filter, referred to as "mechanical filter" or "cartridge filter", is a flat disk of random laid non-woven fiber material which is made of raw materials, e.g., mini-fibers, pulps, glass fibers and activated carbon fibers. After raw materials are mixed in the pure water, dried flat sheet without electrical charge is pleated to expand the surface and placed in the filter cartridge.

The efficiency of a respirator filter medium depends on the characteristics of challenge aerosol and filter. Characteristics of challenge aerosol include particle size, density, electrical charge and flow rate. Filter characteristics, such as packing density, thickness and fiber diameter, which are controlled by the manufacturer, are also influential in determining the filter efficiency ${ }^{4)}$. Filter layers, packing density, aerosol loading and flow rate affect the magnitude of the pressure drop of filter. Since a good respirator filter should have low filter penetration, i.e. high aerosol efficiency 
and low pressure drop, most of all manufacturers try to produce the most efficient filter with the lowest breathing resistance.

\section{Background}

A respirator filter with perfect efficiency and physiologically intolerable high air resistance, i.e. high pressure drop is of no use. Therefore, filter quality using penetration and pressure drop could be considered when ranking respirator. In other words, information on the filter quality of a given respirator would be important to evaluate and make selection. Filter quality is usually expressed by the "quality factor $\left(\mathrm{q}_{\mathrm{F}}\right)$," which relates the aerosol penetration by the filter to the pressure drop across it. The quality factor $\left(\mathrm{q}_{\mathrm{F}}\right)$ is normally used as the indicator of filter performance

$$
\mathrm{q}_{\mathrm{F}}=\frac{\ln (1 / \mathrm{P})}{\Delta \mathrm{p}}
$$

where $\mathrm{P}$ is the fraction of aerosol penetrated and $\Delta \mathrm{p}$ is the pressure drop ${ }^{5}$. This factor should only be used to compare cartridge filters and filtering facepieces in the same respirator categories. The respirators available commercially are labeled for protection against hazardous materials, but in spite of importance of it, information on filter quality is not provided.

The objective of this study is to present basic data on the performance of respirator filters which are widely used in Korea using the quality factor as well as have made comparisons with the performance of them and suggest on direction for improvement of respirator quality.

\section{Experimental Materials and Methods}

Two brands of mechanical filters from different manufacturers were selected for test: a pleated-shaped filter from Company S, termed Mechanical S, and another pleatedshaped filter from Company K, termed Mechanical K, which are the most widely used as mechanical filter. Three brands of filtering facepieces for particulates were evaluated in this study: a cone-shaped filter from Company S, termed Filtering facepiece $S$, which is made in China and imported, another cone-shaped filter from Company $\mathrm{C}$, termed Filtering facepiece $\mathrm{C}$ and other cone-shaped filter from Company $\mathrm{M}$, termed Filtering facepiece M, which is made in USA and imported. All filters were certified by Korean Industrial Safety Corporation (KISCO) under the current regulation ${ }^{6}$. Five respirator filters for each brand were tested as received from the manufacturers without any kind of preconditioning.
An automatic filter tester (CertiTest Model 8110, TSI Inc., St. Paul, USA) in this study was used to measure aerosol penetrated and pressure drop. Solid sodium chloride $(\mathrm{NaCl})$ aerosols were generated by mixing $10 \mathrm{~g}$ of reagent grade salt with each $1 \mathrm{~L}$ of distilled water in the generator of the instrument. Count mean diameter (CMD) of polydisperse aerosol output by this procedure was reported $0.1 \mu \mathrm{m}$ with geometric standard deviation (GSD) of $<1.9$, and therefore $95 \%$ size range of aerosols was about 0.03 to $0.36 \mu \mathrm{m}$, in which includes the most penetrating aerosol size of $0.3 \mu \mathrm{m}$, and the concentration of aerosols varies from 15 to $100 \mathrm{mg} /$ $\mathrm{m}^{3}$ as claimed by the manufacturer ${ }^{7}$. The ionizer was turned on to neutralize the aerosols to Boltzmann charge equilibrium during testing. Aerosol penetration was measured at four constant sampling flow rates of 10, 32, 64 and $85 \pm 4 \mathrm{~L} /$ min, considering the inhalation rates of workers and regulation of certified respirators ${ }^{6,8,9)}$. Room temperature was employed and relative humidity ranged from 65 to $70 \%$ for all the tests. Five filters for each brand were tested and the averages and standard deviations were determined.

\section{Results and Discussion}

The exact combination of filtration mechanism depends upon the flow rate through the filter and the size of particle ${ }^{2}$. Stated briefly, an increase in particle size will cause increased filtration by the interception and inertial impaction mechanisms, whereas a decrease in particle size will enhance collection by Brownian diffusion. Thus there is an intermediate particle size region where two or more of there mechanism take place simultaneously. In this region, since the particle penetration through filters is maximal the collection efficiency is minimal. For most filter type the most penetrating particle size is in the range between 0.1 0.4 $\mu \mathrm{m}$. An increase in flow rate causes a downward shift in the particle size of maximum penetration. For these reasons, National Institute for Occupational Safety and Health (NIOSH) established the new filter certification test in which filter should be tested in the worst condition, e.g., a high work rate of $85 \pm 4 \mathrm{~L} / \mathrm{min}$ for single filters, the most penetrating aerosol size of approximately $0.3 \mu \mathrm{m}$ and chargeneutralized particles and so ${ }^{9}{ }^{9}$. Contrary to USA, the regulations of respirator filter certification in Korea are less sophisticated. KISCO certifies particulate respirator filter media regardless of use such as dust, mist and fume if they filter at least $95 \%$ of $2.0 \mu \mathrm{m}$ or smaller quartz aerosols at flow rate of $30 \mathrm{~L} / \mathrm{min}$ and have at least inhalation and exhalation pressure drop of $6 \mathrm{mmH}_{2} \mathrm{O}$, respectively (4 $\mathrm{mmH}_{2} \mathrm{O}$ for filtering facepieces) at the same flow rate ${ }^{6}$. 
Table 1. Performance of respirator filters using quality factor at each flow rate

\begin{tabular}{|c|c|c|c|c|c|}
\hline Type of filters & Brands & $\begin{array}{c}\text { Flow rates } \\
(\mathrm{L} / \mathrm{min})\end{array}$ & $\begin{array}{l}\text { Pressure drop } \\
\left(\Delta \mathrm{p}, \mathrm{mmH}_{2} \mathrm{O}\right) \\
\text { Average (S.D.) }\end{array}$ & $\begin{array}{c}\text { Penetration } \\
(\mathrm{P}, \%) \\
\text { Average (S.D.) }\end{array}$ & $\begin{array}{l}\text { Quality factors } \\
\left(\mathrm{q}_{\mathrm{F}}, 1 / \mathrm{cm} \mathrm{H}_{2} \mathrm{O}\right)\end{array}$ \\
\hline \multirow[t]{8}{*}{ Mechanical Filter } & $S$ & 10 & $2.51(0.34)$ & $0.34(0.04)$ & 0.2265 \\
\hline & & 32 & $7.10(1.32)$ & $0.85(0.07)$ & 0.0672 \\
\hline & & 64 & $13.65(3.42)$ & $1.30(0.11)$ & 0.0318 \\
\hline & & 85 & $18.35(3.56)$ & $1.68(0.10)$ & 0.0348 \\
\hline & K & 10 & $2.50(0.42)$ & $2.28(0.31)$ & 0.1512 \\
\hline & & 32 & $6.85(1.06)$ & $5.11(0.43)$ & 0.0434 \\
\hline & & 64 & $14.25(2.57)$ & $7.42(0.64)$ & 0.0183 \\
\hline & & 85 & $19.40(3.50)$ & $8.87(0.93)$ & 0.0125 \\
\hline \multirow[t]{12}{*}{ Filtering facepiece } & $S$ & 10 & $3.50(0.61)$ & $3.34(0.05)$ & 0.0971 \\
\hline & & 32 & $7.80(2.52)$ & $5.56(0.57)$ & 0.0370 \\
\hline & & 64 & $16.65(4.42)$ & $13.10(3.11)$ & 0.0122 \\
\hline & & 85 & $21.83(5.65)$ & $21.91(3.67)$ & 0.0070 \\
\hline & M & 10 & $2.51(0.35)$ & $1.30(0.21)$ & 0.1730 \\
\hline & & 32 & $5.30(0.97)$ & $2.48(0.54)$ & 0.0698 \\
\hline & & 64 & $11.82(2.27)$ & $8.47(1.31)$ & 0.0209 \\
\hline & & 85 & $16.69(3.46)$ & $14.90(4.67)$ & 0.0114 \\
\hline & $\mathrm{C}$ & 10 & $3.01(0.45)$ & $2.49(0.36)$ & 0.1227 \\
\hline & & 32 & $6.68(1.67)$ & $5.03(0.76)$ & 0.0448 \\
\hline & & 64 & $14.53(3.93)$ & $13.10(3.09)$ & 0.0140 \\
\hline & & 85 & $20.41(5.32)$ & $19.52(4.30)$ & 0.0080 \\
\hline
\end{tabular}

\section{Penetration and pressure drop}

The purpose of this study is first to evaluate the penetration and pressure drop of particulate respirator filters which are most widely used in Korea. The results of filters tested are described in Table 1. Figure 1 shows the aerosol penetration and pressure drop of mechanical filters at flow rates of 10 , 32, 64 and $85 \mathrm{~L} / \mathrm{min}$. Each line connects the average values obtained from the Table 1 . The magnitudes of both penetrations and pressure drops of all filters increase sharply as the flow rates increase. Like this results the increased penetration with increased flow rate indicates that the aerosol removal mechanisms are diffusion and electrostatic attraction ${ }^{10)}$. The penetrations of filter $\mathrm{S}$ are much lower that those of filter $\mathrm{K}$ at all flow rates. In particular these data shows that filters $\mathrm{K}$ gives lower collection efficiency (1-penetration percentage, $\%$ ) than the $95 \%$ required by the present regulation for filter test near flow rate of $30 \mathrm{~L} / \mathrm{min}$, however, it must be noted that since challenge aerosols used in this study were not 2.0 $\mu \mathrm{m}$ or smaller quartz in the present regulated-protocol but $\mathrm{NaCl}$ having $\mathrm{CMD}$ size of $0.1 \mu \mathrm{m}$, collection efficiency may decrease. This indicates that even through the respirator filters are certified by the regulation, they may be not suitable in the workplace exposed to fume which is size ranged from 0.001 to $1.0 \mu \mathrm{m}$, such as welding work ${ }^{11}$. Compared with filter $\mathrm{K}$, filter $\mathrm{S}$ available commercially is indeed very good in the

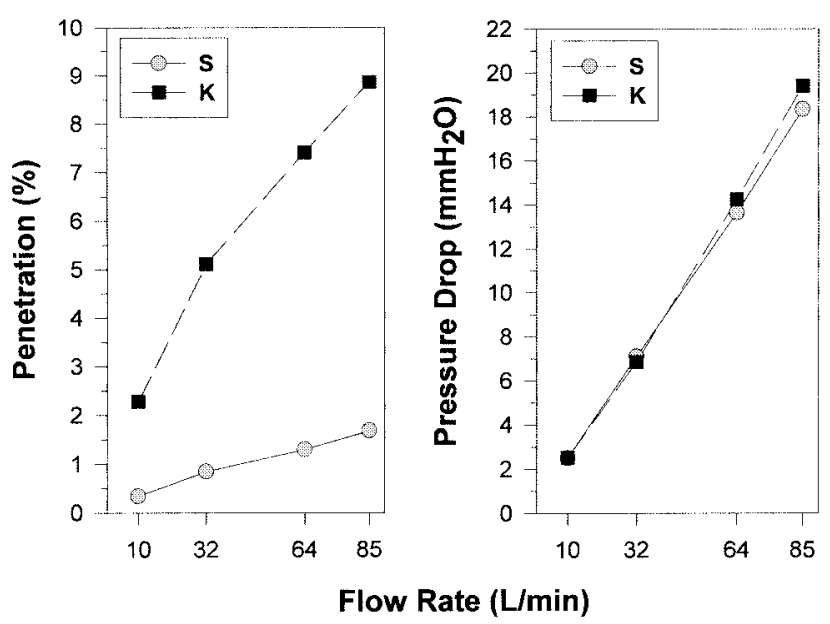

Fig. 1. Aerosol penetration $(\%)$ and pressure drop $\left(\mathrm{mmH}_{2} \mathrm{O}\right)$ of mechanical filters with flow rate.

aspect of efficiency because of having high efficiencies even at high flow rates. The KISCO-regulated allowable resistance requirements for mechanical filters, at a continuous air flow of $30 \mathrm{~L} / \mathrm{min}$ after the quartz test, are $6 \mathrm{mmH}_{2} \mathrm{O}$ at inhalation and $6 \mathrm{mmH}_{2} \mathrm{O}$ at exhaltion ${ }^{6}$. The pressure drops of both filter $\mathrm{S}$ and filters $\mathrm{K}$ are not only higher than those required by the present test protocol near flow rate of $30 \mathrm{~L} / \mathrm{min}$ but also 


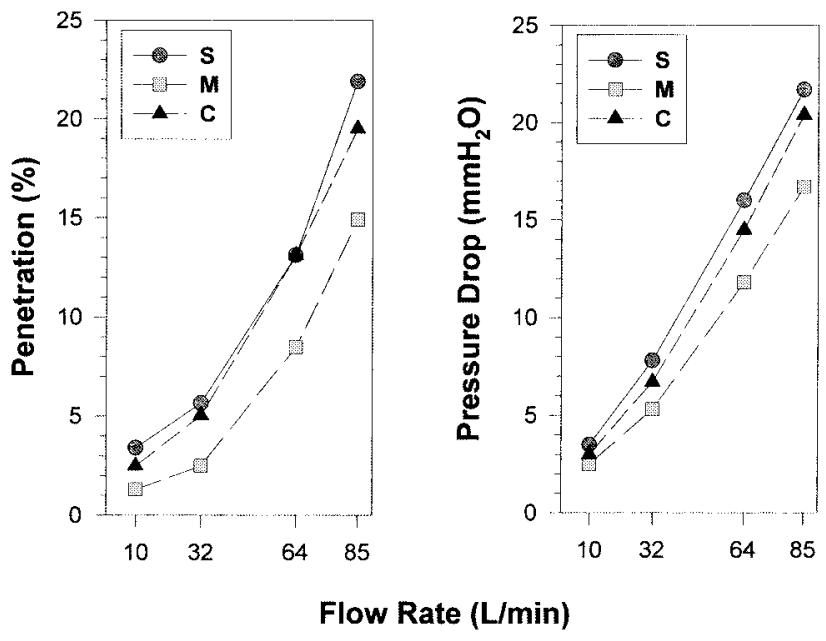

Fig. 2. Aerosol penetration (\%) and pressure drop $\left(\mathrm{mmH}_{2} \mathrm{O}\right)$ of filtering facepieces with flow rate.

increased sharply as the flow rates are increased, even though the test condition in this study was different from the current test protocol. To improve the quality filter $\mathrm{S}$ should be decreased pressure drop. Consequently the manufacturer of filter $\mathrm{S}$ should reduce thickness of the filter layer or use an open lattice network of large diameter fibers as a means of dispersion for small diameter fibers to obtain a high penetration efficiency without simultaneously having a high pressure drop to air flow ${ }^{4}$. In order to be better quality filter $\mathrm{K}$ should be decreased both penetration and pressure drop. Therefore, this study suggests that the manufacturer of filter $\mathrm{K}$ would rather redesign of the filter production process or replace new filter material.

Figure 2 displays the filter penetrations and pressure drops for filtering facepieces and the data are obtained from Table 1. The penetrations and pressure drops have both strong flow rate dependency. Both are increased sharply as flow rates are increased. The sharp increase in aerosol penetrations and pressure drops with increasing flow rate indicates that these filters may not be suitable for a high work load requiring high breathing rates. Therefore, the manufacturers should use more strongly electrostatically charged fibrous filters or change the production process to allow low penetration of particles while also maintaining a low pressure drop across the filters ${ }^{12}$. Since of three brands filter $M$ has the lowest values of penetrations and pressure drops at all flow rates, this implies that it is better than two. Filter $\mathrm{S}$ and $\mathrm{C}$ were certified by the present regulation, but the penetrations in this study reveal 5.56 and $5.03 \%$, respectively. This result indicates that some particulate filters certified by the current regulated test protocol may not protect the wearer from fume exposure. This suggests that the certified test protocol for

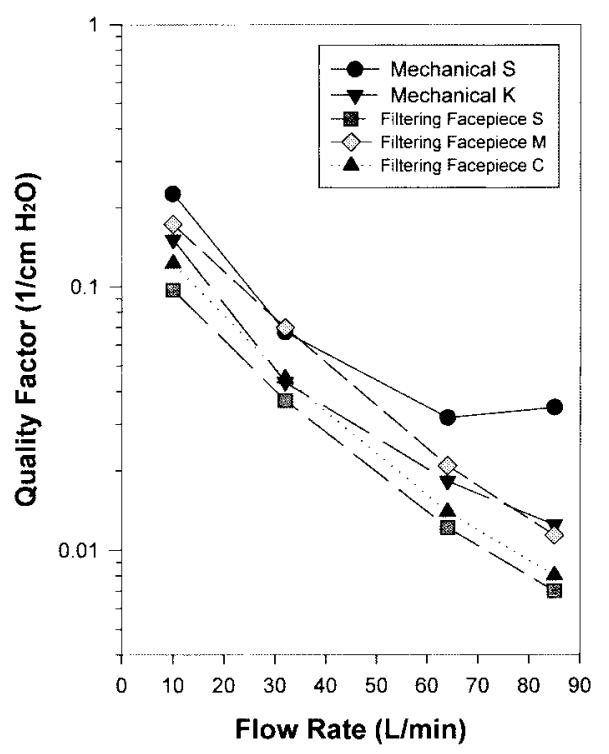

Fig. 3. Quality factors of filters with flow rate.

particulate filters should be revised to be used much smaller size aerosols. The KISCO-regulation requires pressure drop of $4 \mathrm{mmH}_{2} \mathrm{O}$ at both inhalation and exhalation for filtering facepieces at flow rate of $30 \mathrm{~L} / \mathrm{min}^{6}$. Because the pressure drops of three brands are all above $4 \mathrm{mmH}_{2} \mathrm{O}$, manufacturers should make much efforts on decreasing pressure drop, which is affected only slightly by the structure for a given packing density, thickness and fiber diameter ${ }^{13-15}$. Consequently all of the manufacturers should replace the existing fiber materials for with more strongly charged fibrous filters or new fibrous filter materials. Except for filter M, other two filters should be all decreased both penetration and pressure drop to have a better quality.

\section{Filter quality factor}

Each quality factor is shown in Figure 3 in which the data were obtained from Table 1. As stated above, quality factor, including the penetration and pressure drop, should be necessary to rank respirator filters within the same category. As shown in Fig. 3, filter quality factors are strongly dependent on flow rates, decreasing dramatically with flow rates. These results are in agreement with the results reported by others ${ }^{5}$. The variability in filter quality factor with flow rates is high. For example, the quality factor of filtering facepiece $\mathrm{C}$ is 0.0448 at a flow rate of $32 \mathrm{~L} / \mathrm{min}$ and 0.0080 at a flow rate of $85 \mathrm{~L} / \mathrm{min}$; i.e., they have a difference by a factor of 5.6. As expected, having the lowest penetration and pressure drop similar to others, mechanical filter $\mathrm{S}$ has the highest filter quality. This indicates that this filter is 
best engineered to facilitate the air passing through and the aerosol removal effectively simultaneously. In particular, filter quality of mechanical filter S decreases less slowly with increased flow rates than those of others, implying that this filter could be more appropriate at the heavy workload.

According to the previous study reported by others ${ }^{5)}$, quality factor also has strong aerosol size dependency, increasing with increased aerosol size, especially in the supermicrometer size, but this study was not performed in accordance with aerosol size.

A new respirator filter test protocol proposed by KISCO adopt $\mathrm{NaCl}$ aerosols with range size of $0.04 \sim 1.0 \mu \mathrm{m}$ and mean size of about $0.6 \mu \mathrm{m}$ or paraffin oil aerosol with range size of $0.05 \sim 1.7 \mu \mathrm{m}$ and mean size of about $0.4 \mu \mathrm{m}$. This new test protocol adopts flow rates of 30,95 and $160 \mathrm{~L} /$ $\min ^{16}$. This change will make particulate-filter respirator certification a more rigorous process because these sizedaerosols normally have higher aerosol penetration than 2.0 $\mu \mathrm{m}$ or smaller aerosols, especially at high flow rate. On July 1, 2000, the existing respirator filter test protocol will be replaced by the new one ${ }^{16)}$ as an active regulation. As of that date, KISCO no longer accepts applications for new approvals or for extension of approvals under the existing protocol, Notice No. 1997-45. However, the new regulation permits the manufacture and sale of respirators certified under Notice No. 1997-45 until June 30, 2002. This 2-year period will provide time for manufacturers to have new respirators approved and manufactured to demand.

\section{Conclusion}

Collection efficiency and pressure drop are the most important aspects of performance of a respirator filter. Filter quality factor $\left(\mathrm{q}_{\mathrm{F}}\right)$ expressed with aerosol penetration and pressure drop can be used to evaluate and rank the respirator filter in the same category.

Although mechanical filter $\mathrm{K}$, filtering facepiece $\mathrm{S}$ and $\mathrm{C}$ tested were certified, they are not nearly as efficient when tested by much smaller aerosols in this study as when tested with the present regulated protocol. This result raises the question of whether the current certified filter test protocol for respirators regardless of use is appropriate. Filter qualities of mechanical filter $S$ and filtering facepiece $M$ are better than others. Quality control for other respirator filters should be strict to improve better quality during manufacturing.

This study indicates that the new certification test protocol for particulate filter respirators be imperative to make the process of particulate-filter respirator certification more rigorous in Korea.

\section{References}

1) Chen CC, Lehtimäki M, Willeke K (1993) Loading and filtration characteristics of filtering facepieces. Am Ind Hyg Assoc J 54, 51-60.

2) National Institute for Occupational Safety and Health (1987) NIOSH Guide to industrial respiratory protection. 1-52, NIOSH, Cincinnati, Ohio.

3) Moyer ES, Stevens GA (1989) "Worst case" aerosol testing parameters: II. Efficiency dependence of commercial respirator filters on humidity pretreatment. Am Ind Hyg Assoc J 50, 265-70.

4) Revoir WH, Bien C-T (1997) Respiratory protection handbook. 54-56, Lewis Publisher, New York.

5) Chen CC, Lehtimäki M, Willeke K (1992) Aerosol penetration through filtering facepieces and respirator cartridges. Am Ind Hyg Assoc J 53, 556-74.

6) Korean Industrial Safety Corporation (1997) Certification test protocol for particulate respirator filter: Notice No. 1997-45 of Korean Ministry of Labor (1997. 12.29) (in Korean).

7) TSI Incorporated (1990) Operation and service manual for Model 8110 Automated Filter Tester, TSI Inc., St. Paul, Minnesota.

8) Cambell DL (1983) NIOSH File report: Optimum flow rate for aerosol filter testing, 11, NIOSH, Cincinnati, Ohio.

9) National Institute for Occupational Safety and Health (1996) NIOSH Guide to the selection and use of particulate respirators: certified under 42 CFR 84, 6, NIOSH, Cincinnati, Ohio.

10) Hinds WC (1982) Aerosol technology. 164-86, John Wiley \& Sons, New York.

11) American Industrial Hygiene Association (1997) The occupational environments-its evaluation and control. ed. by DiNardi SR, 244-5, AIHA press, Fairfax, Virginia.

12) Lathrache R, Fissan HJ, Neumann S (1986) Deposition of submicron particles on electrically charged fibers. J Aerosol Sci 17, 446-9.

13) Brown RC (1984) A many-fiber model of air flow through a fibrous filter. J Aerosol Sci 15, 583-9.

14) Ingham DB, Heggs PJ, Hildyard ML (1988) A note on the pressure drop across a fibrous filter modifier as a symmetrical array of cylinder. J Aerosol Sci 19, 385-6.

15) Kanaoka C, Hiragi S (1990) Pressure drop of air filter with dust load. J Aerosol Sci 21, 127-37.

16) Korean Industrial Safety Corporation (1998) Certification test protocol of particulate respirator filter: Notice of Proposed Rule, Notice No. 2000-15 of Korean Ministry of Labor (2000. 4.18) (in Korean). 